\title{
Editorial
}

\section{La Constitución de 1991 y el sentimiento constitucional}

\author{
María Cristina Gómez Isaza*
}

El siglo XX terminó con dos acontecimientos constitucionales: los doscientos años de la consagración de las constituciones liberales escritas en los Estados Unidos de América y Francia y el surgimiento del tercer constitucionalismo o neoconstitucionalismo en Latinoamerica con las Constituciones del Brasil (1988), Colombia (1991), Perú (1994) y Venezuela (1999).

Colombia ingresó a este tercer ciclo de las luchas por la democracia hace 30 años y hoy podríamos desearnos "Happy Constitution, feliz celebración". (Clavero, 1997, pág. 9). Celebramos un pacto de paz que, a pesar de la incertidumbre y del miedo, hizo coincidir los objetivos de la sociedad civil y la sociedad política en la construcción de un proyecto de supervivencia fundado en la democracia participativa y la defensa de los derechos humanos.

Celebramos a la Constitución de 1991 como la oportunidad histórica de transformación y deconstrucción de la cultura constitucional de la regeneración política y de sus principios de unidad nacional excluyente y homogeneizador, confesionalismo y estado de sitio, para construir una nueva cultura constitucional basada en principios como el reconocimiento de una sociedad pluriétnica, el estado laico y la creación de un Estado Social de Derecho, unitario con autonomía de las regiones.

Varias promesas se han incumplido, entre las que se destacan el déficit de democracia participativa en razón del recrudecimiento del conflicto armado (Uribe de Hincapie, 2001.); la negación de la autonomía territorial y la recentralización

Profesora titular de la Facultad de Derecho y Ciencias Políticas de la Universidad de Antioquia, Colombia. Correo electrónico: mcristina.gomez@udea.edu.co Orcid: https://orcid.org/0000-0002-0973-9341

Doi: 10.17533/udea.esde.v78n172a00 
política (Acosta, 2021); y se ha mantenido el presidencialismo, alentado por la confrontación entre las jurisdicciones y entre la jurisdicción y el Congreso.

Sin embargo, al hacer el balance crítico de la Constitución de 1991 no podemos caer en extremos: "por un lado la tendencia a eliminar la importancia de los diseños institucionales o el vicio opuesto de considerar que todos los problemas sociales pueden ser resueltos por la ingeniería constitucional" (Uprimny, 2002, pág. 61). Para ello es necesario analizar los contextos sociales y las políticas que favorecen o dificultan que una Constitución cumpla sus promesas y aspiraciones.

El contexto social nos develará la cultura constitucional, esa que se constituye por el compromiso particular y colectivo de vivir en Constitución y por la apropiación de sus prácticas democráticas. La cultura constitucional es la vivencia permanente de su utopía, ${ }^{1}$ que se traduce en el anhelo de vivir en una sociedad equitativa, solidaria, tolerante, respetuosa de la diferencia, y que tramita sus conflictos por medio del diálogo.

El "sentimiento constitucional", ${ }^{2}$ reflejo de la cultura constitucional de una sociedad, la interpela en tres aspectos: ¿Para qué quiero una Constitución?; ¿Qué justifica la existencia del Estado? Y ¿Cuál es el tipo de sociedad en la que queremos construir nuestros proyectos de vida, tanto individuales como colectivos?

¿Para qué quiero una Constitución? A lo largo de doscientos la Constitución fue un instrumento para someter, reprimir y excluir a los opositores (los distintos) y para transformarlos en enemigos, o para buscar homogeneizar la sociedad. Con la Constitución de 1991 hay que celebrar el inicio de una transformación cultural, pues su vigencia coincide con la expectativa de alcanzar la paz a través de ella.

¿Qué justifica la existencia del Estado? Las guerras y el conflicto armado justificaban la existencia del Estado para crear el orden y la seguridad. Celebramos la existencia de la utopía vigente desde 1991 con la ilusión y el anhelo de un Estado que se justifica para garantizar los derechos, un Estado Social de Derecho que reconoce la dignidad humana y que construimos, a pesar de la crisis del bienestar y de la implementación del modelo económico neoliberal globalizado.

La sociedad de la Constitución de 1991 se aleja de la versión homogénea de nación heredada de la Regeneración, en la que solo participaban los hombres

1 “Para la interpretación de los conceptos constitucionales quizá resulta más fructífero partir del paradigma poético que del paradigma narrativo. La palabra poética emerge, además, como símbolo aglutinante al que el constituyente recurre para dotar de estabilidad al sistema; sería un factor emocional e integrador que permite preservar el consenso en torno a las estructuras básicas del Estado “ (Habërle, P. López Boffil, C. 2015, pág 15.)

2 "Se podría describir como aquella conciencia de la comunidad que, trascendiendo a todos los antagonismos y tensiones existentes politicopartidistas, economicosociales, religiosos o de otro tipo, integra a detentadores y destinatarios del poder en el marco de un orden comunitario obligatorio, jsutamente la Constitución, sometiendo el proceso politico a la comunidad" (Loewestein,1983, pág 200). 
blancos, católicos que hablaban español (Arango, 2004) y, para ello, reivindicó nuestra realidad pluriétnica, reconoció que las mujeres mantuvimos el tejido social a pesar de la guerra, y aceptó las diferencias ideológicas y religiosas, para iniciar el difícil camino hacia la tolerancia y el respeto, negado por el odio y el resentimiento de años de violencia y de confrontación social.

Treinta años después, constatamos la existencia de una cultura constitucional propia, que denomino cultura épica. En efecto, en Colombia, a pesar de la guerra, nuestra cultura constitucional ha mantenido la ilusión de un compromiso permanente con la paz y con los derechos fundamentales, así como las expectativas de construir un diálogo social a pesar del miedo a ser acallados. Es la cultura que lucha por el reconocimiento, a pesar de los resentimientos y de los prejuicios heredados de nuestra violencia.

La guerra con su sino fatal de violencia y de dolor no ha impedido sentir que la Constitución de 1991 puede ser un proyecto de vida, en el que la igualdad y la libertad comprendan la necesaria fraternidad que, como principio, plantea que nadie, bajo ninguna condición, puede vivir sometido a nadie.

La revista Estudios de Derecho celebra los 30 años de la Constitución Política con este número temático. Los ocho artículos que comprenden este texto tienen el sentido de nuestra cultura épica constitucional: la defensa de la democracia, la garantía de nuestros derechos, el reconocimiento de la diferencia, y la proscripción de la guerra y de la violencia.

Quien lea cada uno de los textos que conmemoran nuestra celebración constitucional encontrará que sus autores nos recuerdan el compromiso que suscribimos de crear esperanza, de sobrevivir a nuestros miedos e incertidumbres.

“¿Una fuente bíblica para el principio de separación de poderes?” escrito por Juan David Ramírez Echeverri tiene por objetivo recordar el fundamento de la separación de poderes como principio fundamental para el cosntitucionalismo, su carácter, naturaleza y finalidad. Al leer este artículo, el autor nos recuerda el compromiso en torno al estado laico, una revisión de las ganancias de la libertad religiosa y la lucha por la tolerancia, que inició en nuestro país con la Constitución de 1991. Este texto describe, de manera erudita y amena, la lucha por liberar a Athenas de Jerusalem, lucha que involucra las libertades y la igualdad.

"Monopolio, mercado de servicios jurídicos y acceso a la justicia: notas para un futuro debate" de Sergio Iván Anzola Rodríguez recopila las sentencias de la Corte Constitucional sobre el monopolio de los abogados y sobre las reglas creadas por la Corte que estructuran y afectan el mercado de los servicios jurídicos en nuestro país. En este artículo se hace un recuento de las justificaciones del monopolio que se otorga a las y los abogados en materia jurídica; explica las formas en que dicho mercado es regulado por el Estado y advierte acerca de los riesgos de mantener el monopolio de los servicios jurídicos, así como de relajarlo. 
"Treinta años de aspiraciones constitucionales de paz para el cambio social" de Juan Carlos Ospina y David Fernando Cruz es un artículo esperanzador en la construcción de la paz en nuestro país. Nos recuerda que la paz es plural, como la sociedad que vive en conflicto y su aspiración debe ser desinstitucionalizada (no dejarla sólo en manos del Estado). Para hacer realidad la paz debemos articular perspectivas transdiciplinarias, compromiso social y apuestas incompletas, todas ellas en la vía de la utopía. A pesar de que el cambio social derivado de un orden constitucional toma tiempo, requiere compromiso, pues la paz es un anhelo y un proceso. Los autores sugieren que la paz es un conflicto de aspiraciones que tiene diversas aproximaciones que deben concitarse. Esas diversas aproximaciones tienen dos tendencias: la primera que determina que la precondición de la paz misma es la reconciliación y, la segunda, la convivencia, que es precondición de una paz estable y duradera.

"La Constitución de 1991 y la contratación estatal. Visiones conflictivas y deficiencias en el diseño del Estado" de Diana Carolina Valencia-Tello analiza una práctica típica del presidencialismo: la deslegalización con el fin de cumplir con los estándares de los procesos de privatización y reducción del estado impuestos por los organismos internacionales. El caso concreto que trata la autora es el del estatuto de contratación estatal que ha sido modificado por vía de decretos. La regulación actual del Sistema de Compras Públicas en Colombia se ha hecho luego de diágnosticos hechos por el BM, la OCDE, la OCD, que luego son utilizados en documentos Conpes, directivas presidenciales, decretos y resoluciones. Estas regulaciones han modificado sustancialmente la Ley 80 de 1993. Concluye la autora que la mayoría de las normas en materia de contratación son expedidas por el gobierno nacional, conforme a recomendaciones dadas por organismos internacionales, sin debate del Congreso de la República, tal como lo establece nuestra Constitución.

"La resistencia por el derecho a la tierra en Colombia: entre la especificación y el apartheid constitucional" de Andrés Camilo Ramírez Gutiérrez describe el derecho a la tierra desde nuestro origen constitucional. Para el autor, en Colombia el derecho a la tierra se ha definido bajo dos elementos: la coerción y la regulación liberal de la propiedad. El derecho a la tierra durante el siglo XX se reguló para sincronizar la apropiación de la tierra y de la violencia, mientras que la regulación del derecho a la tierra durante siglo XXI introdujo la categoría jurídica de víctima para concretar los derechos sobre la tierra o la propiedad rural. La voz de la Corte Constitucional también es invitada en este escrito, la cual, para su autor, define la propiedad agraria desde una visión liberal-occidental ligada al desarrollo económico, lo que ha incidido en la falta de acceso de los sujetos campesinos al derecho a la tierra y ha posibilitado su bloqueo desde las élites, y desde algunas instituciones del Estado en la restitución de tierras. Estos bloqueos impiden el reconocimiento pleno de los derechos del campesinado y mantienen el apartheid constitucional. 
"Constitucionalismo y democracia: análisis desde el caso colombiano en los 30 años de la expedición de la Constitución de 1991" escrito por Andrea Celemín Caicedo nos plantea la necesaria revisión de la democracia y del constitucionalismo como "slogans". Para la autora, nos hemos preocupado más por la democracia sustancial que la procedimental. El artículo propone dotar de sentido a la representación política. Ello crearía los espacios de debate democráticos que harían posible el equilibrio de los poderes públicos y, con ello, evitar el activismo judicial y el presidencialismo. Para la autora, con el advenimiento de la Constitución de 1991, el derecho constitucional colombiano ha estado más preocupado por llenar de contenido el eslogan del constitucionalismo, de manera que no nos hemos comprometido con la revisión del principio democrático y con su operación en las instituciones representativas.

El artículo “Comportamiento discursivo del enunciado territorio ancestral en las sentencias de la Corte Constitucional de Colombia" de Joice Johana Barbosa Becerra analiza el discurso de la Corte Constitucional y cómo el lenguaje jurídico, bajo el principio de progresividad del derecho, han ido ampliando los derechos constitucionales establecidos en el proceso constituyente de 1991. Estas dos condiciones, las disputas por el poder decir de los pueblos indígenas y una Corte con enfoque de derechos, han procurado, paulatinamente, permear de ancestralidad los discursos duros del campo jurídico.

Finalmente, César Augusto Benavidez Vega hace un análisis de la incidencia del activismo judicial en la definición del alcance del ámbito competencial de las autoridades de distintos niveles, en la decisión sobre la extracción de recursos naturales no renovables en la sentencia SU-095 de 2018 de la Corte Constitucional. En su artículo “¿Gobierno de los jueces o gobierno del pueblo? Consultas populares ambientales y activismo judicial en Colombia?", concluye que el activismo de nuestra Corte Constitucional sustituye el gobierno del pueblo por el gobierno de los jueces.

Los artículos de este número conmemorativo son el reflejo de nuestra utopía convertida en épica constitucional: paz, derechos, democracia, participación, igualdad, libertad, territorio. Solo queda por decir que la interpretación de esta cultura no claudica y ha sido la que mantiene a la Constitución de 1991 viva y en la calle.

Utopía - Eduardo Galeano

Qué tal si deliramos por un ratito

qué tal si clavamos los ojos más allá de la infamia

para adivinar otro mundo posible 
El aire estará limpio de todo veneno que no provenga

de los miedos humanos y de las humanas pasiones

En las calles los automóviles serán aplastados por los perros

la gente no sera manejada por el automóvil

ni será programada por el ordenador

ni será comprada por el supermercado

ni será tampoco mirada por el televisor

El televisor dejará de ser el miembro más importante de la familia

y será tratado como la plancha o el lavarropas

Se incorporará a los códigos penales el delito de estupidez

que cometen quienes viven por tener o por ganar

en vez de vivir por vivir no más

como canta el pájaro sin saber que canta

y como juega el niño sin saber que juega

En ningún país irán presos los muchachos

que se nieguen a cumplir el servicio

sino los que quieran cumplirlo

Nadie vivirá para trabajar

pero todos trabajermos para vivir

Los economistas no llamarán nivel de vida al nivel de consumo

ni llamarán calidad de vida a la cantidad de cosas

Los cocineros no creerán que a las langostas les encanta que las hiervan vivas Los historiadores no creerán que a los países les encanta ser invadidos Los políticos no creerán que a los pobres les encanta comer promesas

La solemnidad se dejará de creer que es una virtud y nadie nadie tomará en serio a nadie que no sea capaz de tomarse el pelo

La muerte y el dinero perderán sus mágicos poderes

y ni por defunción ni por fortuna

se convertirá el canalla en virtuoso caballero

La comida no será una mercancía

ni la comunicación un negocio

porque la comida y la comunicación son derechos humanos 
Nadie morirá de hambre

porque nadie morirá de indigestion

Los niños de la calle no serán tratados como si fueran basura

porque no habrá niños de la calle

Los niños ricos no serán tratados como si fueran dinero

porque no habrá niños ricos

La educación no será el privilegio de quienes puedan pagarla

y la policía no será la maldición de quienes no puedan comprarla

La justicia y la libertd, hermanas siamesas condenadas a vivir separadas volverán a juntarse bien pegaditas espalda contra espalda

En Argentina las locas de Plaza de Mayo serán un ejemplo de salud mental porque ellas se negaron a olvidar en los tiempos de la amnesia obligatoria

La santa madre iglesia corregirá algunas erratas de las tablas de Moisés y el 6 to mandamiento ordenará festejar el cuerpo

La iglesia dictará tambien otro mandamiento que se le había olvidado a Dios: amarás a la naturaleza de la que formas parte

Serán reforestados los desiertos del mundo

y los desiertos del alma

Los desesperados serán esperados

y los perdidos serán encontrados

porque ellos se desesperaron de tanto esperar

y ellos se perdieron por tanto buscar

Seremos compatriotas y contemporáneos de todos los que tengan

voluntad de belleza y voluntad de justicia

hayan nacido cuando hayan nacido

y hayan vivido donde hayan vivido

sin que importen ni un poquito las fronteras del mapa ni del tiempo

Seremos imperfectos

Porque la perfección seguirá siendo

el aburrido privilegio de los dioses

pero en este mundo

en este mundo chambón y jodido

seremos capaces de vivir cada día

como si fuera el primero 
y cada noche

como si fuera la última

\section{Referencias Bibliográficas:}

Acosta, A. (2021) bajado https://www.larepublica.co/analisis/amylkar-d-acostam-557896/la-recentralizacion-3098205.

Arango, R. (2004). Derechos, Constitucionalismo y Democracia. Bogotá: Universidad Externado.

Clavero, B. (1997). Happy Constitution. Cultura y lengua constitucionales. Madrid: Trotta.

Ochoa, R. Veinte años de la Constitución, Editorial, Revista Estudios de Derecho Universidad de Antioquia, No 151, Junio 2011.

Haberle, P. López Boffil, H. (2015). Poesia y Derecho Constitucional. Centro de Estudios Constitucionales - Tribunal Constitucional del Perú: Lima.

Uprimny, R. Constitución de 1991, Estado Social y Derechos Humanos: promesas incumplidas, diagnóstico y perspectivas Universidad Nacional de Colombia, ILSA: Bogotá. Pp 55-75.

Uribe, M.T. (2001). Constitución y Democracia participativa en Debate a la Constitución. Universidad Nacional de Colombia, ILSA: Bogotá . Pp 191-208. 